\title{
Study on the Development Height of Overburden Water-Flowing Fracture Zone of the Working Face
}

\author{
Ke Ding $\left(\mathbb{D},{ }^{1}\right.$ Lianguo Wang $\mathbb{D},{ }^{1}$ Wenmiao Wang $\mathbb{D}^{2},{ }^{2}$ Kai Wang, ${ }^{1}$ Bo Ren $\mathbb{D},{ }^{1}$ \\ and Chongyang Jiang ${ }^{1}$ \\ ${ }^{1}$ State Key Laboratory for Geomechanics and Deep Underground Engineering, China University of Mining and Technology, Xuzhou, \\ Jiangsu 221116, China \\ ${ }^{2}$ School of Mines, China University of Mining and Technology, Xuzhou, Jiangsu 221116, China
}

Correspondence should be addressed to Lianguo Wang; cumt_lgwang@163.com

Received 9 February 2021; Revised 9 February 2021; Accepted 4 March 2021; Published 18 March 2021

Academic Editor: Yi Xue

Copyright ( $) 2021 \mathrm{Ke}$ Ding et al. This is an open access article distributed under the Creative Commons Attribution License, which permits unrestricted use, distribution, and reproduction in any medium, provided the original work is properly cited.

\begin{abstract}
Mining-induced fractures in underground coal mining face affect the stability of overburdens and provide preferential channels for water and material transfer in the underground environment. Therefore, to study the development of waterflowing fracture zones in overburdens of working face and goaf is of great significance for roof control, gas drainage, water resistance, disaster reduction, and efficient mining from the mining. In this study, a new method for predicting the development of overburden water-flowing fracture zone height (DHOWFFZ) was proposed based on the characteristics of overburden rock in No. 3 coal seam of Xin'an Coal Mine. First, the stope of No. 3 coal seam exhibits a rock stratum structure of mudstone and sandstone overlapping. Considering this characteristic, the overburden strata of No. 3 coal seam are divided into several "mudstone-sandstone" rock stratum groups. Furthermore, the ultimate tensile deformation of soft rock is greater than that of hard rock. It is proposed to judge the development degree of penetrating fracture in each rock stratum by adopting the elongation rate of mudstone intermediate layer. Meanwhile, the DHOWFFZ of "mudstone sandstone" composite rock stratum structure in the 3402 working face of No. 3 coal seam is calculated to be smaller than $43.1 \mathrm{~m}$ according to the actual situation. Finally, the DHOWFFZ in the 3402 working face was measured in the field, which verifies the rationality of the new DHOWFFZ prediction method. The research results provide new ideas for the prediction of DHOWFFZ and are helpful for future research in related fields.
\end{abstract}

\section{Introduction}

The repaid development of China's economic situation is pushing large-scale coal mining area growth and development. However, the large-scale mining of coal resources has caused great damage to the surrounding environment and communities and brought irreparable losses to people's production and life [1-3]. These problems are all related to the deformation and damage of the overburdens caused by the mining of coal resources. Therefore, how to effectively predict the deformation and cracking of the overburdens of the mining coal seams has a very important practical significance for the protection of the overlying aquifers and surface water resources and the prediction of mine water damage accidents [4-6].
The overburden water-flowing fracture zone is not only an important indicator reflecting the damage of overburdens but also a crucial channel for water flowing into the goaf and causing various mine disasters. Therefore, the development height of overburden water-flowing fracture zone (DHOWFFZ) is an important technical parameter for safe mining under a mine water body. Its height is an intuitive description of the shape of the water-flowing fracture zone. At present, field observation is the most accurate method to determine the DHOWFFZ, and the commonly used observation methods include underground double-end water plugging observation method, surface drilling flushing fluid consumption observation method, high-density resistivity method, and television imaging 
method [7-9]. However, the traditional empirical formula method is generally adopted in the prediction of DHOWFFZ currently in China because the complex field observation operation may affect the efficient production in coal mines. The traditional empirical formula method is $H=(1 \sim 3)\left(m-S_{A}\right) /\left(K_{A}-1\right) m$, where $H$ is DHOWFFZ; $m$ is the coal seam thickness; $S_{A}$ is the settlement value of the rock beam at the gangue is generally selected according to the empirical value; and $K_{A}$ is the coefficient of broken expansion of the fallen rock strata at the gangue of the rock beam $[10,11]$. In recent years, extensive indepth researches have been conducted on the prediction of DHOWFFZ, showing promising results. The empirical formula for DHOWFFZ prediction in China is developed based on the summary of vast data obtained during coal mining. Since only the mining thickness of coal seam is considered in the formula, the calculated results are quite different from the actual measured results in practical application, indicating certain limitations [12]. When investigating DHOWFFZ, scholars at home and abroad have recognized the deficiency of the empirical formula method and have proposed various new theories and methods to accurately estimate the value of DHOWFFZ research. Abbas et al. [13] proposed a new parameter influencing the DHOWFFZ, namely, the lithology proportion factor of hard rock, which avoided the statistical determination of uniaxial compressive strength involved in the classification of various roof types in the currently used standards; $\mathrm{Hu}$ et al. [14] put forward a new DHOWFFZ prediction method based on the position of key overburdens strata. Chai et al. [15] established a GASVR mining DHOWFFZ prediction model and verified by practice that the accuracy of the model could meet the actual requirements. Adhikary and Guo [16] revealed a theoretical DHOWFFZ calculation method for fully mechanized mining by constructing three models, i.e., (i) a complete mechanical model of rock stratum suspension, (ii) a model of rock stratum overhanging, and (iii) breaking and a mechanic model of broken rock block. Huang et al. [17] proposed a new DHOWFFZ prediction method of calculating overlying bedrock composite structure and rock stratum tensile deformation. In general, current researches on the DHOWFFZ are still in the stage of exploration and experience accumulation.

The roof of coal seam in Xin'an Coal Mine is composed of mudstone and sandstone. Each rock stratum possesses a "mudstone-sandstone" composite structure comprising a lower layer of hard sandstone and an upper layer of soft mudstone. In this study, based on the characteristics of mudstone and sandstone crosscombination in the roof of No. 3 coal seam in Xin'an Coal Mine. A new method for calculating the DHOWFFZ is proposed in light of the calculation method of horizontal tensile deformation of soft rock stratum. The method works by calculating the elongation rates of mudstone intermediate layers in rock stratum groups and analyzing the law of fracture development in rock strata. The new DHOWFFZ prediction method is suitable for "mudstone-sandstone" composite rock stratum structure.

\section{Analysis of the Influence of "Mudstone- Sandstone" Composite Rock Stratum Structure on the Development of Water- Flowing Fracture Zone}

2.1. Engineering Geology. Xin'an Coal Mine is located in Liuzhuang Town, Weishan County, Shandong Province, China. The surface above the mine is Weishan Lake which covers an area of about $1266 \mathrm{~km}^{2}$. Coal-bearing strata of the mine belong to Shanxi Formation and Taiyuan Formation, and No. 3 coal seam with an average thickness of $8.7 \mathrm{~m}$ is the main mining coal seam. No. 3 coal seam is affected by two layers of aquifers in the mine: (1) the first is a sandstone karst fracture aquifer located $55-89 \mathrm{~m}$ above No. 3 coal seam. With a thickness of $12.6-21.1 \mathrm{~m}$ and a unit water inflow of 0.02483 $0.79245 \mathrm{~L} / \mathrm{s} \cdot \mathrm{m}$, the aquifer belongs to a weak to medium water-rich aquifer. (2) The second is roof and floor sandstone aquifers in No. 3 coal seam. The roof and floor sandstones, both mainly composed of fine sandstone, are 8.0-45.4 $\mathrm{m}$ and 4.1-10.6 $\mathrm{m}$ in thickness, respectively. With a unit water inflow of $0.0369-0.16434 \mathrm{~L} / \mathrm{s} \cdot \mathrm{m}$, the aquifers belong to weak waterrich fractured confined aquifers. To avoid the effect of waterflowing fracture zone on the water body, the development rule of water-flowing fracture zone is analyzed by taking the 3402 working face of Xin'an Coal Mine as an example. The position of 3402 working face is displayed in Figure 1.

The ground elevation and elevation of the 3402 working face are $+31.56 \sim+32.52 \mathrm{~m}$ and $-525.6 \sim-604.2 \mathrm{~m}$, respectively. The mining coal seam is No. 3 coal seam whose average thickness and average dip angle are $8.7 \mathrm{~m}$ is $9^{\circ}$, respectively. The overburden roof, which belongs to medium hard rock strata in terms of overall structure, is mainly composed of mudstone and sandstone. The specific rock structure within $70 \mathrm{~m}$ of overburdens above the working face is exhibited in Figure 2.

As can be seen from Figure 2, there are 9 layers of weak mudstones and sandy mudstones and 7 layers of hard fine sandstones and siltstones within $70 \mathrm{~m}$ of overburdens above the working face. The overburdens are characterized by obvious stratification. From No. 3 sandy mudstone upward, each layer of mudstone is separated by a layer of sandstone, and the overburdens exhibit a rock stratum structure of mudstone and sandstone overlapping. Moreover, each layer of mudstone shares a similar thickness with the adjacent layer of sandstone above.

The roof rock was collected from the 3402 working face of No. 3 coal seam in Xin'an Coal Mine and processed into cylindrical samples with a diameter of $50 \mathrm{~mm}$ and heights of $100 \mathrm{~mm}$ and $25 \mathrm{~mm}$ and cubic samples with a side length of $100 \mathrm{~mm}$. Then, sample density was obtained using MH-300Z mineral rock densitometer. Further, classical mechanical testing was performed to obtain their uniaxial compression strength, tensile strength, and shear resistance, as shown in Figures 3-5. The corresponding data acquired were analyzed to obtain the mechanical parameters of each rock layer.

The test results of mechanical parameters of rock layers within $70 \mathrm{~m}$ above the roof of No. 3 coal seam in Xin'an Coal Mine are listed in Table 1. It can be known by testing the basic mechanical parameters that the mechanical properties of sandstone layers in the roof differ slightly, and those of 


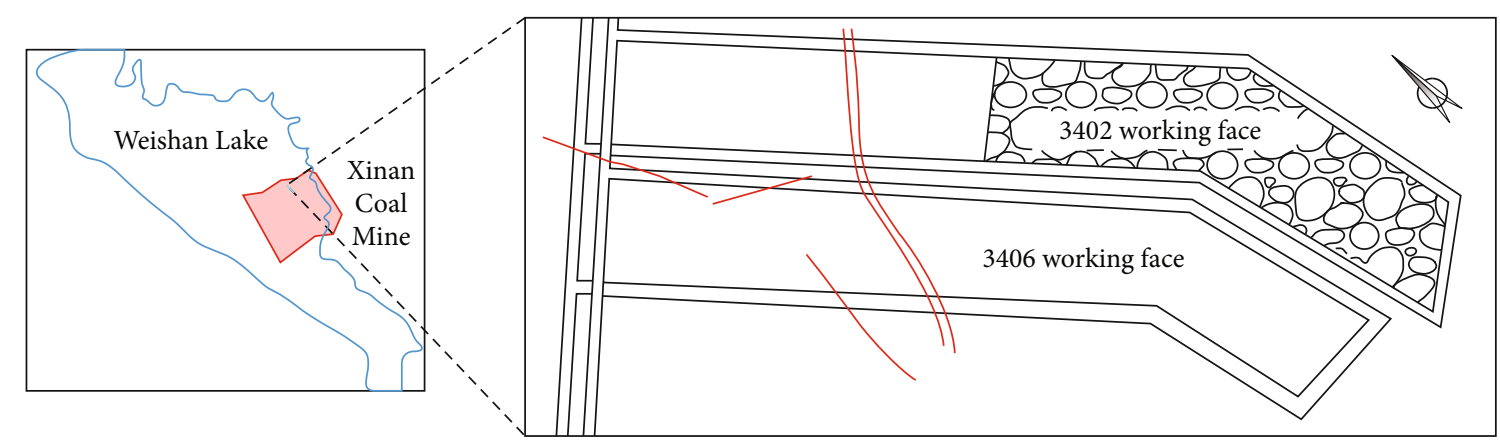

FIgURE 1: Position map of 3402 working face.

\begin{tabular}{|c|c|c|c|c|c|}
\hline \multicolumn{6}{|l|}{$+32.0 \mathrm{~m}$} \\
\hline & Order & Lithology & Thickness (m) & $\begin{array}{c}\text { Distance to } \\
\text { coal seam } \\
\text { roof }(\mathrm{m})\end{array}$ & $\begin{array}{c}\text { Rock } \\
\text { association }\end{array}$ \\
\hline & 18 & Conglomerate & 17.3 & 67.7 & \\
\hline & 17 & Mudstone & 4.3 & 50.4 & \multirow{2}{*}{ Rock formation 7} \\
\hline & 16 & Fine sandstone & 3.0 & 46.1 & \\
\hline & 15 & Mudstone & 4.8 & 43.1 & \multirow{2}{*}{ Rock formation 6} \\
\hline & 14 & Fine sandstone & 4.6 & 38.3 & \\
\hline & 13 & Mudstone & 2.4 & 33.7 & \multirow{2}{*}{ Rock formation 5} \\
\hline & 12 & Siltstone & 1.5 & 31.3 & \\
\hline & 11 & Mudstone & 1.4 & 29.8 & \multirow{2}{*}{ Rock formation 4} \\
\hline & 10 & Fine sandstone & 3.8 & 28.4 & \\
\hline & 9 & Mudstone & 6.7 & 24.6 & \multirow{2}{*}{ Rock formation 3} \\
\hline & 8 & Fine sandstone & 2.5 & 17.9 & \\
\hline & 7 & Mudstone & 3.3 & 15.4 & \multirow{2}{*}{ Rock formation 2} \\
\hline & 6 & Fine sandstone & 4.0 & 12.1 & \\
\hline & 5 & Mudstone & 2.4 & 8.1 & \multirow{2}{*}{ Rock formation 1} \\
\hline & 4 & Fine sandstone & 3.0 & 5.7 & \\
\hline & 3 & Sandy mudstone & 1.3 & 2.7 & \\
\hline & 2 & Mudstone & 1.4 & 1.4 & \\
\hline & 1 & No.3 coal & 8.7 & 0 & \\
\hline
\end{tabular}

Figure 2: Overburden stratum structure.

mudstone layers in the roof are also similar. Besides, the strength of sandstone is greater than that of mudstone.

\subsection{Analysis of "Mudstone-Sandstone" Composite Rock} Stratum Structure. Numerous previous studies have revealed that after the coal seam is mined, the overburdens bend and subside in the form of stratum groups. In each stratum group, a layer of hard rock at the bottom drives the upper layers of softer rock to move synchronously and coordinately. The movement and combination of rock strata are determined by the strength factors (including lithology, thickness, elastic modulus) of each rock stratum. The upper rock stratum with low strength factors will move simultaneously with the lower rock stratum with high strength factors, and the ultimate elongation rate of upper rock stratum with low strength factors is higher than that of lower rock stratum with high strength factors [18].

The fully mechanized caving coal mining technology is adopted in the working face of No. 3 coal seam in Xin'an Coal Mine. As the working face advances, the relatively weak mudstone $1.4 \mathrm{~m}$ above No. 3 coal seam and sandy mudstone $1.3 \mathrm{~m}$ above No. 3 coal seam will collapse together with the remaining coal in the process of coal caving. As illustrated in Figure 1, from No. 4 rock stratum upwards, the roof of No. 3 coal seam exhibits a rock stratum structure of mudstone and sandstone overlapping, and each layer of 


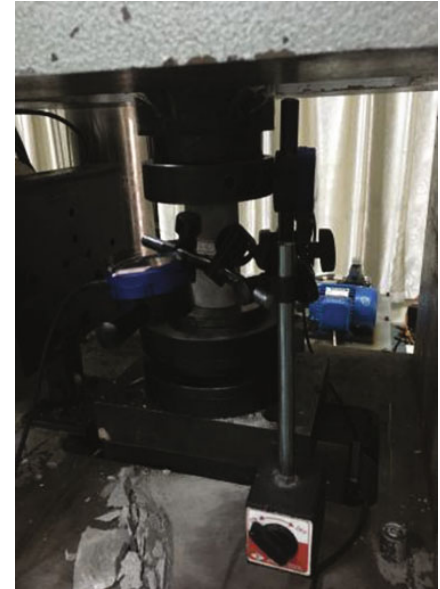

FIgURe 3: Uniaxial compression test.

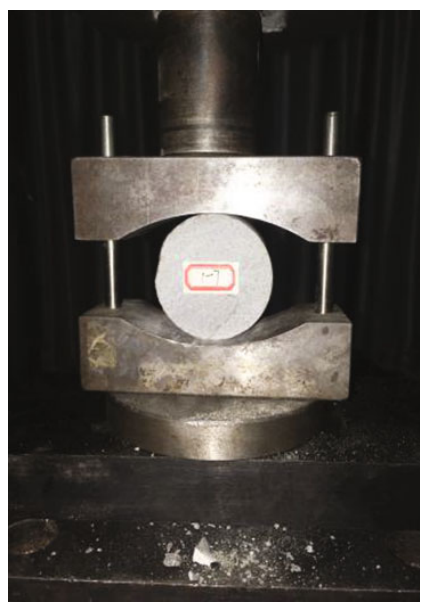

Figure 4: Brazilian splitting test.

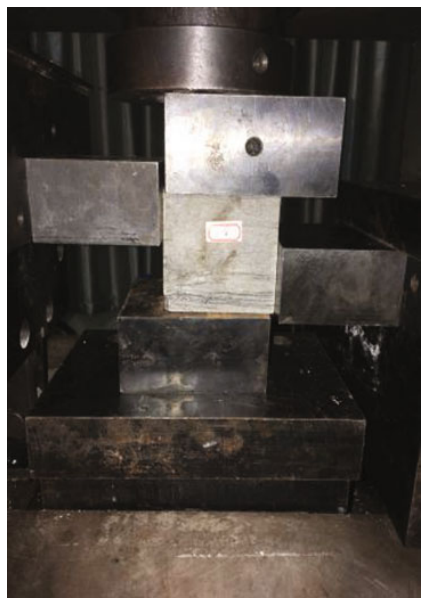

FIgURE 5: Shear resistance experiment.

mudstone shares a similar thickness with the adjacent layer of sandstone above. According to this characteristic, the roof overburden strata of No. 3 coal seam are divided into 7 rock stratum groups, each comprising a sandstone layer and a mudstone layer. Since the strength of sandstone is greater than that of mudstone and the thicknesses of mudstone and sandstone are similar in each group, it can be inferred that the fracture development of each rock stratum group is controlled by the movement of sandstone in the lower part, and the mudstone and sandstone move synchronously and coordinately. In addition, since the ultimate elongation deformation of soft rock is greater than that of hard rock [19], it is assumed that when the mudstone fails to form a fracture as it undergoes tensile deformation, the water-flowing fracture zone develops at most to the rock stratum group where the mudstone is located. Therefore, the maximum DHOWFFZ can be determined by analyzing and judging whether mudstone tensile deformation in each rock stratum group can lead to the formation of enough penetrating fractures which enable water to flow smoothly.

2.3. Analysis of Rock Stratum Deformation Criterion for the DHOWFFZ. According to the above analysis, with the overburden strata divided into groups, the judgment of DHOWFFZ can be transformed into the analysis of tensile deformation of the 7 layers of mudstone. Since the mudstone above the working face is soft rock, compared with the original horizontal state, the mudstone in the deformed state will be elongated as it bends and subsides, as shown in Figure 6. The tensile deformation value of the soft layer is a comprehensive parameter reflecting the development of fractures in rock strata. The fracture development degree and hydraulic conductivity of soft rocks share a direct causal relationship with the tensile deformation of rock [20]. Hence, the elongation rate of mudstone intermediate layer can be regarded as a criterion to analyze the fracture development degree and hydraulic conductivity of "mudstone-sandstone" composite rock stratum structure.

The deformation curve of mudstone is divided into three sections, namely, the approximately horizontal section in the middle and the elongated curve sections on both sides. The deformation increased by the subsidence and elongation of rock intermediate layer is mainly concentrated in the curve sections of the subsided basin. Therefore, the deformation rate $\varepsilon$ of rock intermediate layer can be expressed as

$$
\varepsilon=\frac{\left(l_{1}-l_{0}\right)}{l_{0}},
$$

where $l_{0}$ is the length of rock intermediate layer before bending and deformation and $l_{1}$ is the arc length of the curve sections of rock intermediate layer after bending and deformation.

By means of fitting the two arcs, two parameters required for the calculation of layer elongation rate $\varepsilon$ are obtained:

$$
l_{0}=h_{j}\left(\cot \delta_{0}+\cot \varphi_{0}\right) \text {, }
$$

$$
l_{1}=\left(w_{j}^{2}+l_{0}^{2}\right) \operatorname{artsin}\left[2 w_{j} l_{0} /\left(w_{j}^{2}+l_{0}^{2}\right)\right] \pi /\left(180 \times 2 w_{j}\right), .
$$

where $h_{j}$ is the height of the $j$ th rock intermediate layer (m); $h_{j}=\sum_{i=1}^{j-1} h_{i}+h_{0} / 2$ in which $\sum_{i=1}^{j-1} h_{i}$ is the total thickness of 
TABLE 1: Test results of physical and mechanical parameters.

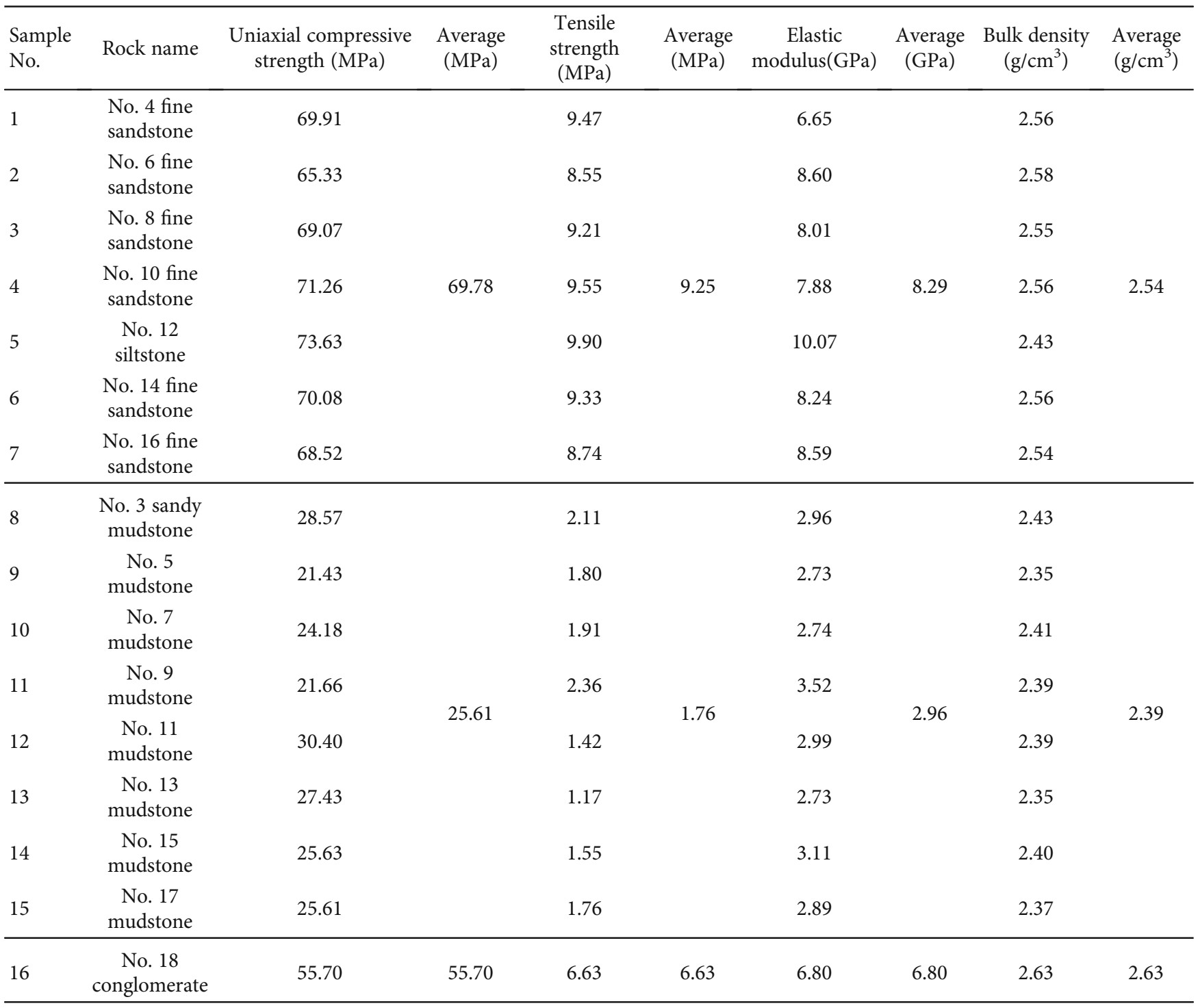

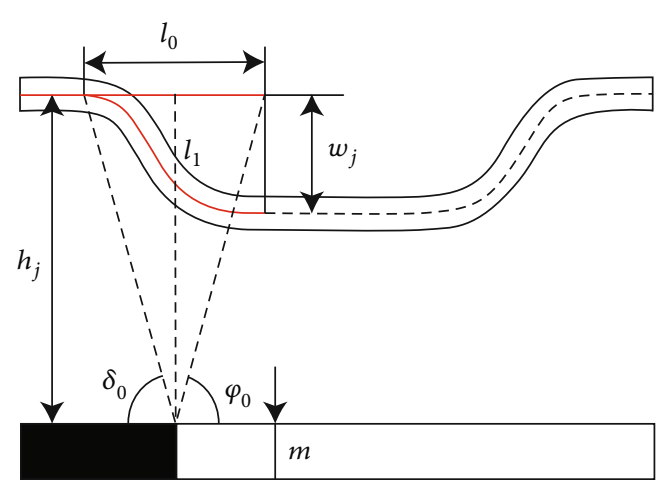

Figure 6: Sketch map of tensile deformation of rock stratum.

lower layers (m); $h_{0}$ is the thickness of the rock layer, $m ; \delta_{0}$ is the mining boundary angle of the coal seam; $\varphi_{0}$ is the angle of full mining; and $w_{j}$ is the maximum subsidence of the rock stratum group where the $j$ th layer of mudstone is located (m).
According to the research [21], the size of free movement space of rock stratum is a key factor that determines the bending and subsidence of rock stratum and the full development of penetrating fractures. And the free space formed after mining of coal seams will be filled by fractured and expanded overburden rock. By taking into account the bulking coefficient of each rock layer, the maximum subsidence $w_{j}$ of a certain mudstone intermediate layer in the "mudstone-sandstone" composite rock stratum structure can be calculated according to Equation (4):

$$
w_{j}=m-\sum_{i=1}^{j-1} h_{i}\left(k_{i}-1\right)
$$

where $m$ is the mining thickness of coal seam (m) and $k_{i}$ is the residual bulking coefficient of sandstone in the ith group below. 
TABLE 2: Calculation parameters of layer elongation rate.

\begin{tabular}{|c|c|c|c|c|c|c|c|}
\hline Rock layer & $\begin{array}{c}\text { Height of rock } \\
\text { intermediate layer }(\mathrm{m})\end{array}$ & $\begin{array}{c}\text { Cot } \\
\delta_{0}\end{array}$ & $\begin{array}{c}\text { Cot } \\
\varphi_{0}\end{array}$ & $\begin{array}{l}\text { Mining } \\
\text { thickness (m) }\end{array}$ & $\begin{array}{l}\text { Bulking coefficient of } \\
\text { rock layer }\end{array}$ & $\begin{array}{l}\text { Maximum subsidence of } \\
\text { rock layer }(\mathrm{m})\end{array}$ & $\begin{array}{c}\text { Layer } \\
\text { elongation rate } \\
\varepsilon \\
\end{array}$ \\
\hline $\begin{array}{l}\text { No. } 5 \\
\text { mudstone }\end{array}$ & 8.64 & 0.577 & 0.577 & 8.70 & 1.14 & 5.92 & $22.07 \%$ \\
\hline $\begin{array}{l}\text { No. } 7 \\
\text { mudstone }\end{array}$ & 15.49 & 0.577 & 0.577 & 8.70 & 1.13 & 5.16 & $5.54 \%$ \\
\hline $\begin{array}{l}\text { No. } 9 \\
\text { mudstone }\end{array}$ & 22.99 & 0.577 & 0.577 & 8.70 & 1.12 & 4.60 & $2.15 \%$ \\
\hline $\begin{array}{l}\text { No. } 11 \\
\text { mudstone }\end{array}$ & 30.84 & 0.577 & 0.577 & 8.70 & 1.11 & 3.64 & $0.70 \%$ \\
\hline $\begin{array}{l}\text { No. } 13 \\
\text { mudstone }\end{array}$ & 34.24 & 0.577 & 0.577 & 8.70 & 1.11 & 3.33 & $0.53 \%$ \\
\hline $\begin{array}{l}\text { No. } 15 \\
\text { mudstone }\end{array}$ & 42.44 & 0.577 & 0.577 & 8.70 & 1.11 & 2.56 & $0.12 \%$ \\
\hline $\begin{array}{l}\text { No. } 17 \\
\text { mudstone }\end{array}$ & 49.99 & 0.577 & 0.577 & 8.70 & 1.10 & 2.18 & $0.09 \%$ \\
\hline
\end{tabular}

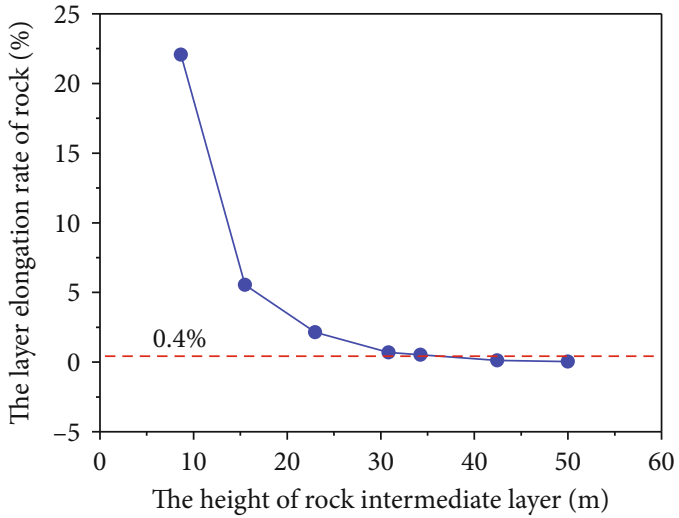

FIGURE 7: Relationship curve between the layer elongation rate of rock and the height of rock intermediate layer.

The elongation rate of a certain mudstone intermediate layer above the coal seam roof can be obtained by combining Equations (1)-(4). It can be seen that the elongation rate $\varepsilon$ of a rock layer is mainly affected by factors such as the height of the rock stratum group, the thickness of the stratum, the bulking coefficient of sandstone in the rock stratum group, the boundary angle, and the angle of full mining.

The bulking coefficient of caved immediate roof in the goaf can be measured in the field, but that of upper rock strata can hardly be accurately measured in the field. The value of bulking coefficient, however, directly influences the subsidence space of different rock strata. According to the researches $[22,23]$, the smaller the size of fragmented rock block is, the greater the bulking coefficient is. Besides, in the vertical direction, with the increase of distance from the goaf, the size of fragmented rock block increases rapidly, and the residual bulking coefficient of it gradually decreases as a logarithmic function. The relationship between the average bulking coefficient $k$ and the distance from the mining coal seam hi (i.e., the total thickness of lower rock strata) can be expressed by the function $k=\mathrm{kz}-0.017$ lnhi $(h \mathrm{i}<100)$ where $\mathrm{kz}$ is the bulking coefficient of the immediate roof below [24-26]. $\cot \delta_{0}=\cot \varphi_{0}=0.577$ in accordance with Regulations on Coal Pillar Retention and Coal Mining under Buildings, Water Bodies, Railways and Main Shafts [5]. The data of working face suggest that the recovery rate of the 3402 working face is $80 \%$. Given the recovery rate, the actual mining height of coal in the working face is about $6.96 \mathrm{~m}$, and the rest of coal and roof strata are broken together and left in the goaf. Therefore, kz takes the value of the bulking coefficient of coal, namely, 1.17, according to the field test. Combined with Figure 2, the values of calculation parameters of the elongation rate of mudstone intermediate layer are given in Table 2.

For full comparison and explanation, the elongation rates of mudstone intermediate layers in these rock stratum groups were collated, based on which the fitting curve between the layer elongation rate of rock and the height of rock intermediate layer was plotted, as disclosed in Figure 7.

As can be observed from Figure 7, the relationship between the layer elongation rate of rock and the height of rock intermediate layer is a negative exponential function. The closer the rock layer is to the working face, the higher its layer elongation rate is, indicating that the more seriously it bends and subsides. As the height of rock layer increases, the layer elongation rate decreases as a negative exponential function. For soft rocks such as mudstone and sandy mudstone, the critical elongation rate of the rock layer is over $0.4 \%$. That is, when the elongation rate of the rock layer is lower than $0.4 \%$, the upward development of the waterflowing fracture zone can be restrained. Thus, the elongation rate drops from $0.53 \%$ to $0.12 \%$ from No. 13 mudstone to No. 15 mudstone, which is a turning point for the layer elongation rate. After passing this turning point, the elongation rates of mudstone layers are all lower than $0.4 \%$. This demonstrates that no penetrating fractures are generated in No. 15 mudstone which basically stays out of the range of the 


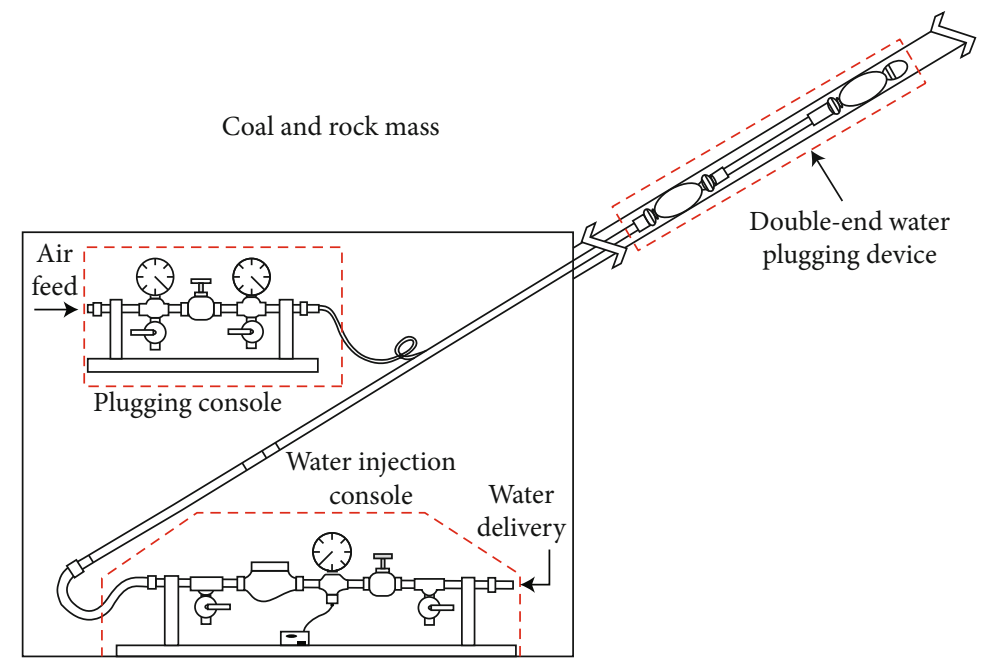

FIGURE 8: Working principle of observation instrument.

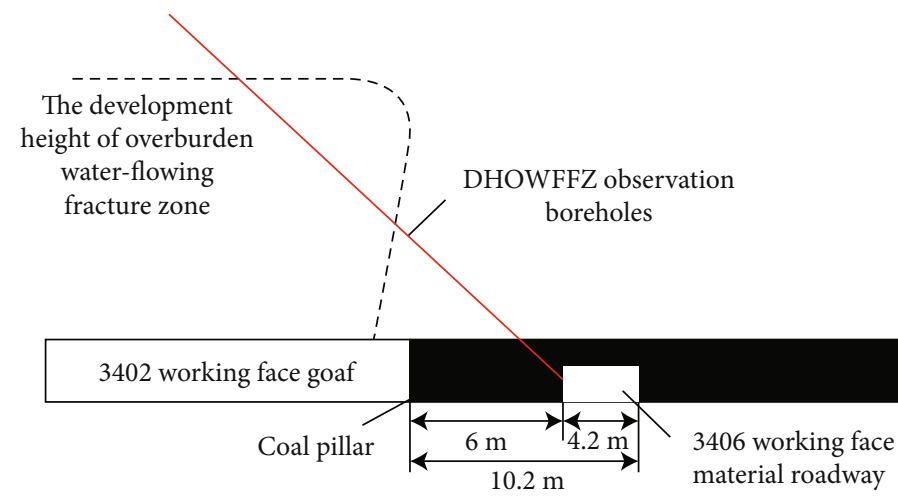

FIGURE 9: Schematic diagram of measurement borehole arrangement.

water-flowing fracture zone. It can be concluded that the DHOWFFZ does not exceed the height of the 6th rock stratum group, namely, $43.1 \mathrm{~m}$.

\section{Field Measurement of DHOWFFZ}

The field measurement was conducted by the method of underground double-end water plugging observation with the aid of a DHOWFFZ observation instrument. The working principle and structure of the observation instrument are shown in Figure 8. Observation points were arranged in the adjacent 3406 working face material roadway, and DHOWFFZ observation boreholes were constructed to the roof above the goaf of the 3402 working face. The coal pillar in the section is $6 \mathrm{~m}$ wide. The length of each constructed observation borehole should exceed the expected DHOWFFZ a little. During the observation, the method of plugging and water injection observation in sections (each observation section: 1-2 m long) was adopted to observe the DHOWFFZ from the bottom of the borehole to the top of it. In the observation process, the water leakage amount will differ greatly when the probe reaches different areas inside and outside the fracture zone. Therefore, the fracture devel- opment degree and water conductivity of rock layer can be judged by the changes in water leakage amounts in the rock layer sections. In this way, the DHOWFFZ can be determined accurately. The schematic diagram of DHOWFFZ observation borehole arrangement is presented in Figure 9.

The results of DHOWFFZ observation are shown in Figure 10. The elevation angle of borehole is $40-45^{\circ}$. It is calculated that before the borehole depth reaches $9 \mathrm{~m}$, the borehole is located in the rock mass above the protective coal pillar of the working face. In this section, the rock stratum is less affected by mining, so no observation was conducted here [27]. When the water leakage amount becomes large (generally about $20-30 \mathrm{~L} / \mathrm{min}$ ), the borehole has penetrated into the fracture zone. With the increase of borehole depth, the water leakage amount drops rapidly to about 5$10 \mathrm{~L} / \mathrm{min}$ which means that the rock layer in this section no longer conducts water. The results of water injection observation reveals that the water leakage amount of borehole 1 changes greatly at the borehole depth of $50.8 \mathrm{~m}$ and the vertical depth of $38.9 \mathrm{~m}$ (an obvious turning point). It can thus be judged that the DHOWFFZ measured through borehole 1 is about $38.9 \mathrm{~m}$. Similarly, the DHOWFFZs measured through boreholes 2, 3, 4, 5, 6, and 7 are given in Table 3. 


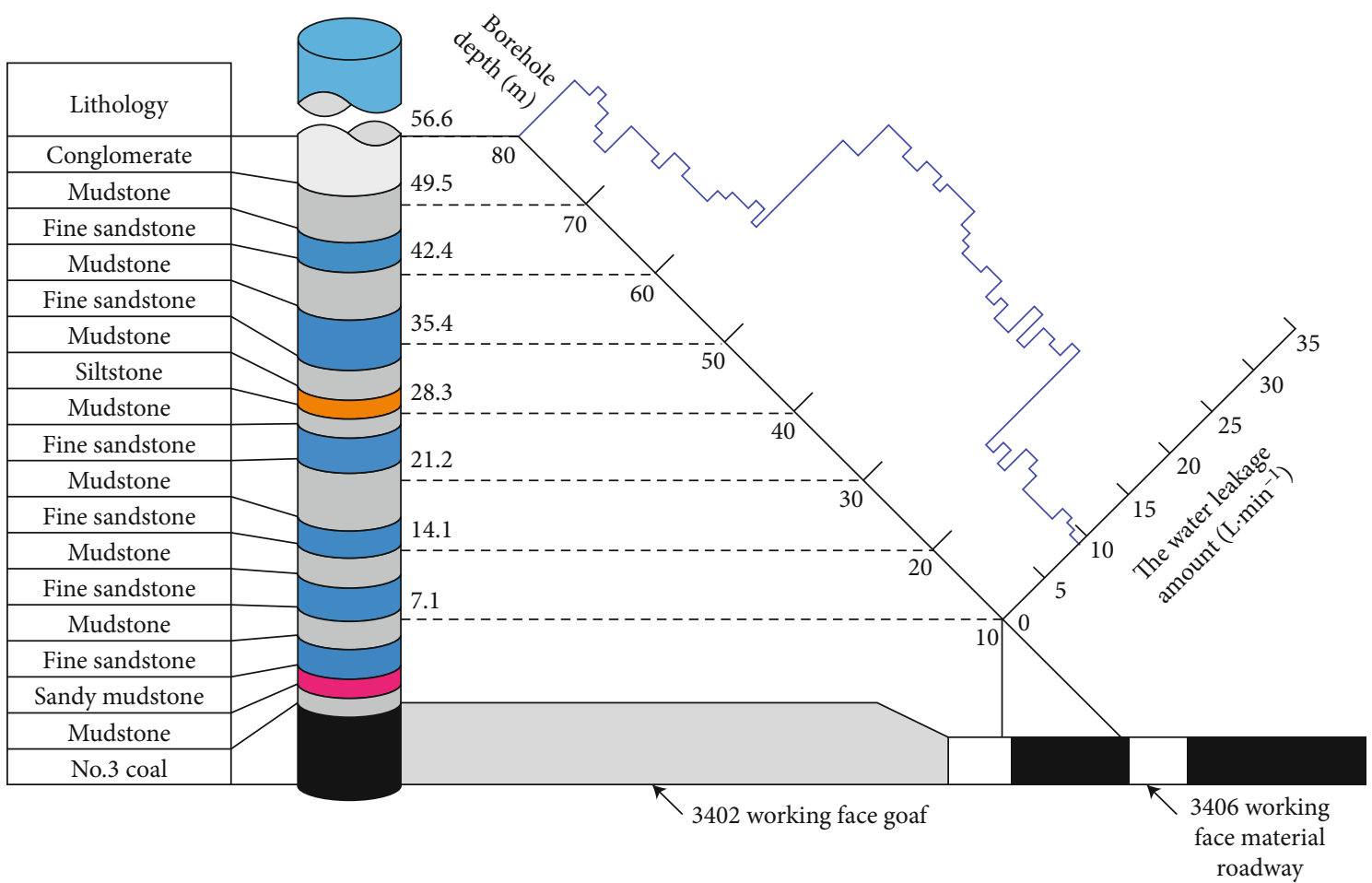

FIgURE 10: Water leakage amount of borehole 1.

TABLE 3: Measuring results of water-flowing fracture zone.

\begin{tabular}{lccc}
\hline $\begin{array}{l}\text { Observation } \\
\text { borehole }\end{array}$ & $\begin{array}{c}\text { Elevation } \\
\text { angle }\left({ }^{\circ}\right)\end{array}$ & $\begin{array}{c}\text { Length } \\
(\mathrm{m})\end{array}$ & $\begin{array}{c}\text { Height of water-flowing } \\
\text { fracture zone }(\mathrm{m})\end{array}$ \\
\hline Borehole 1 & 45 & 80 & 38.9 \\
Borehole 2 & 40 & 85 & 35.9 \\
Borehole 3 & 43 & 80 & 39.6 \\
Borehole 4 & 45 & 80 & 38.2 \\
Borehole 5 & 40 & 85 & 36.4 \\
Borehole 6 & 45 & 80 & 41.3 \\
Borehole 7 & 42 & 85 & 39.7 \\
\hline
\end{tabular}

Here is a comparison between the theoretical analysis and the field measurement. The theoretical analysis shows that the DHOWFFZ is smaller than $43.1 \mathrm{~m}$; the waterflowing fracture zone finally develops into the rock layer below No. 14 fine sandstone; and No. 14 fine sandstone is classified into the range of the bending subsidence zone. The field measurement suggests that the DHOWFFZs all lie in the range of 35.9-41.3 $\mathrm{m}$ which is in line with the theoretical calculation results and does not exceed the height from the goaf to No. 15 mudstone $(43.1 \mathrm{~m})$. This demonstrates that although No. 15 mudstone undergoes a certain bending and subsidence, its tensile fracture only develops in the middle and lower parts of the rock stratum, and its subsidence is not enough to cause the development of a penetrating fracture which covers the whole thickness of the rock. Thereby, it can be inferred that the final DHOWFFZ will not exceed the height of No. 15 mudstone. In the field application, considering a certain safety factor, the maximum value $(41.3 \mathrm{~m})$ measured on site is taken as the DHOWFFZ. The field measurement results verify the rationality of the DHOWFFZ prediction method of "mudstone-sandstone" composite rock stratum structure based on the soft rock elongation rate. This indicates that for the "mudstone-sandstone" composite rock stratum structure, it is reasonable to judge the development degree of penetrating fracture in the rock stratum by adopting the elongation rate of the mudstone intermediate layer. By virtue of this method, the range of DHOWFFZ can be obtained.

\section{Conclusions}

(1) By combining the actual geological characteristics of Xin'an Coal Mine with the results of laboratory mechanical tests, the rock stratum structure characteristics in the stope of Xin'an Coal Mine are obtained as follows: The overburden roof exhibits a rock stratum structure of mudstone and sandstone overlapping, and each layer of mudstone shares a similar thickness with the adjacent layer of sandstone above. However, their mechanical properties differ significantly. A layer of hard rock at the bottom drives the upper layers of softer rock to move synchronously and coordinately. Therefore, the overburden rock strata are divided into several "mudstone-sandstone" rock stratum groups, each comprising one lower sandstone layer with high strength factors and one upper mudstone layer with low strength factors. The overburdens of the working face are gradually developed upward in the form of the abovementioned "mudstonesandstone" rock stratum groups. 
(2) In light of the literature, the ultimate tensile deformation of soft rock is greater than that of hard rock. Therefore, only when the soft mudstone in a rock stratum group bends and deforms and undergoes the formation of a penetrating fracture can the rock stratum group be completely classified as a part of the water-flowing fracture zone. It is proposed to judge the development degree of penetrating fracture in each rock stratum by adopting the elongation rate of mudstone intermediate layer, and the range of DHOWFFZ is judged according to the changes in the elongation rate of the mudstone layer in each rock stratum group. Through calculation, the DHOWFFZ of "mudstone-sandstone" composite rock stratum structure in the 3402 working face is smaller than $43.1 \mathrm{~m}$.

(3) The DHOWFFZ in the 3402 working face was measured in the field, and the measured results are all smaller than the theoretically predicted values. The field measurement verifies the rationality of the DHOWFFZ prediction method of "mudstone-sandstone" composite rock stratum structure based on the soft rock elongation rate. Furthermore, it is determined that the water-flowing fracture zone will not affect the overburden aquifer above No. 3 coal seam of Xin'an Coal Mine, and the mining of No. 3 coal seam is safe and feasible.

\section{Data Availability}

The data used to support the findings of this study are included within the article.

\section{Conflicts of Interest}

The authors declare that they have no conflicts of interest.

\section{Acknowledgments}

This study was supported by the National Key Research and Development Program of China (No. 2017YFC0603004) and the support is gratefully acknowledged.

\section{References}

[1] W. B. Guo, Y. F. Zou, and Q. L. Hou, "Fractured zone height of longwall mining and its effects on the overburden aquifers," International Journal of Mining Science and Technology, vol. 22, no. 5, pp. 603-606, 2012.

[2] D. P. Adhikary and H. Guo, "Modelling of longwall mininginduced strata permeability change," Rock Mechanics and Rock Engineering, vol. 48, no. 1, pp. 345-359, 2015.

[3] Z. Zhao, W. Sun, S. J. Chen, D. W. Yin, H. Liu, and B. S. Chen, "Determination of critical criterion of tensile-shear failure in Brazilian disc based on theoretical analysis and meso-macro numerical simulation," Computers and Geotechnics, vol. 134, article id 104096, p. 62, 2021.

[4] Y. L. Tan, Q. Ma, Z. H. Zhao et al., "Cooperative bearing behaviors of roadside support and surrounding rocks along gob-side," Geomechanics and Engineering, vol. 18, no. 4, pp. 439-448, 2019.

[5] State Bureau of Coal Industry, Specification for Coal Pillar Retention and Coal Mining in Buildings, Water Bodies, Railways and Main Wells and Alley, Coal Industry Press, Beijing, 2017.
[6] Y. Tai, H. C. Xia, and T. J. Kuang, "Failure characteristics and control technology for large-section chamber in compound coal seams-a case study in Tashan Coal Mine," Energy Science and Engineering, vol. 8, no. 4, pp. 1353-1369, 2020.

[7] W. Y. Guo, Y. Qiu, T. B. Zhao, Y. L. Tan, S. Lan, and W. G. Chen, "Influence of the variable stoping speed on the occurrence mechanism of rock burst," Geomatics, Natural Hazards and Risk, vol. 10, no. 1, pp. 2094-2105, 2019.

[8] S. C. Hu, Y. L. Tan, H. Zhou et al., "Anisotropic modeling of layered rocks incorporating planes of weakness and volumetric stress," Energy Science and Engineering, vol. 8, no. 3, pp. 789803, 2020.

[9] B. Ghabraie, G. Ren, X. Zhang, and J. Smith, "Physical modelling of subsidence from sequential extraction of partially overlapping longwall panels and study of substrata movement characteristics," International Journal of Coal Geology, vol. 140, pp. 71-83, 2015.

[10] Y. Zhang, S. H. Tu, Q. H. Bai, and J. J. Li, "Overburden fracture evolution laws and water-controlling technologies in mining very thick coal seam under water-rich roof," International Journal of Mining Science and Technology, vol. 23, no. 5, pp. 693-700, 2013.

[11] W. Y. Guo, Q. H. Gu, T. L. Tan, and S. C. Hu, "Case studies of rock bursts in tectonic areas with facies change," Energies, vol. 12, no. 7, p. 1330, 2019.

[12] C. Liu, J. H. Xue, G. F. Yu, and X. Y. Cheng, "Fractal characterization for the mining crack evolution process of overlying strata based on microseismic monitoring technology," International Journal of Mining Science and Technology, vol. 26, no. 2, pp. 295-299, 2016.

[13] A. Majdi, F. P. Hassani, and M. Y. Nasiri, "Prediction of the height of destressed zone above the mined panel roof in longwall coal mining," International Journal of Coal Geology, vol. 98, no. 1, pp. 62-72, 2012.

[14] G.-L. Hu, W.-B. Zhu, and X.-Z. Wang, "New method to predict the height of fractured water-conducting zone by location of key strata," Journal of China Coal Society, vol. 37, no. 5, pp. 762-769, 2012.

[15] H. B. Chai, J. P. Zhang, and C. H. Yan, "Prediction of waterflowing height in fractured zone of overburdens strata based on GA-SVR," Journal of Mining \& Safety Engineering, vol. 35, no. 2, pp. 359-365, 2018, (In Chinese).

[16] V. Palchik, "Bulking factors and extents of caved zones in weathered overburden of shallow abandoned underground workings," International Journal of Rock Mechanics and Mining Sciences, vol. 79, pp. 227-240, 2015.

[17] W. P. Huang, Y. F. Gao, B. Wang, and J. R. Liu, "Evolution rule and development height of permeable fractured zone under combined-strata structure," Journal of Mining o Safety Engineering, vol. 34, no. 2, pp. 330-335, 2017, (In Chinese).

[18] G. W. Cheng, C. X. Chen, T. H. Ma, H. Y. Liu, and C. N. Tang, "A case study on the strata movement mechanism and surface deformation regulation in Chengchao underground iron mine," Rock Mechanics and Rock Engineering, vol. 50, no. 4, pp. 1011-1032, 2017.

[19] B. Ghabraie, G. Ren, J. Smith, and L. Holden, "Application of 3D laser scanner, optical transducers and digital image processing techniques in physical modelling of mining-related strata movement," International Journal of Rock Mechanics and Mining Sciences, vol. 80, pp. 219-230, 2015. 
[20] W. Y. Guo, F. H. Yu, Y. L. Tan, and T. B. Zhao, "Experimental study on the failure mechanism of layer-crack structure," Energy Science \& Engineering, vol. 7, no. 6, pp. 2351-2372, 2019.

[21] H. Hu, X. Lian, and Y. Li, "Physical experiments on the deformation of strata with different properties induced by underground mining," Journal of Engineering Science and Technology Review, vol. 9, no. 1, pp. 74-80, 2016.

[22] E. Fathi Salmi, M. Nazem, and M. Karakus, "Numerical analysis of a large landslide induced by coal mining subsidence," Engineering Geology, vol. 217, pp. 141-152, 2017.

[23] B. Ghabraie, K. Ghabraie, G. Ren, and J. Smith, "Numerical modelling of multistage caving processes: insights from multi-seam longwall mining-induced subsidence," International Journal for Numerical and Analytical Methods in Geomechanics, vol. 41, no. 7, pp. 959-975, 2017.

[24] Y. Xue, T. Teng, F. Dang, Z. Ma, S. Wang, and H. Xue, "Productivity analysis of fractured wells in reservoir of hydrogen and carbon based on dual-porosity medium model," International Journal of Hydrogen Energy, vol. 45, no. 39, pp. 20240-20249, 2020.

[25] M. An, F. Zhang, D. Elsworth, Z. Xu, Z. Chen, and L. Zhang, "Friction of Longmaxi shale gouges and implications for seismicity during hydraulic fracturing," Journal of Geophysical Research: Solid Earth, vol. 125, no. 8, article e2020JB019885, 2020.

[26] F. Zhang, B. Damjanac, and S. Maxwell, "Investigating hydraulic fracturing complexity in naturally fractured rock masses using fully coupled multiscale numerical modeling," Rock Mechanics and Rock Engineering, vol. 52, no. 12, pp. 51375160, 2019.

[27] Z. Meng, X. Shi, and G. Li, "Deformation, failure and permeability of coal-bearing strata during longwall mining," Engineering Geology, vol. 208, pp. 69-80, 2016. 